\title{
Gaps in addressing cardiovascular risk in rheumatoid arthritis: assessing performance using cardiovascular quality indicators
}

\begin{tabular}{|r|l|}
\hline Journal: & The Journal of Rheumatology \\
\hline Manuscript ID & 2016-0241.R1 \\
\hline Manuscript Type: & Manuscript \\
\hline Complete List of Authors: & $\begin{array}{r}\text { Barber, Claire; University of Calgary, Rheumatology } \\
\text { Esdaile, John; The Arthritis Research Centre of Canada, } \\
\text { Martin, Liam; University of Calgary } \\
\text { Faris, Peter } \\
\text { Barnabe, Cheryl; University of Calgary, Internal Medicine; } \\
\text { Guo, Selynne } \\
\text { Lopatina, Elena } \\
\text { Marshall, Deborah; University of Calgary, Medicine and Community Health } \\
\text { Sciences }\end{array}$ \\
\hline Keywords: & $\begin{array}{l}\text { Rheumatoid arthritis, Cardiovascular diseases, quality indicators, Primary } \\
\text { prevention }\end{array}$ \\
\hline & \\
\hline
\end{tabular}


Title: Gaps in addressing cardiovascular risk in rheumatoid arthritis: assessing performance using cardiovascular quality indicators

Authors: Claire E. H. Barber, John M. Esdaile, Liam O. Martin, Peter Faris, Cheryl Barnabe, Selynne Guo, Elena Lopatina, Deborah A. Marshall

\begin{abstract}
Objectives: Cardiovascular disease (CVD) is a major comorbidity for patients with rheumatoid arthritis (RA). The study sought to determine performance on 11 recently developed CVD Quality Indicators (QIs) for RA in clinical practice.
\end{abstract}

Methods: Medical charts for RA patients (early disease or biologic-treated) followed at one centre were retrospectively reviewed. A systematic assessment of adherence to 11 QIs over a two-year period was completed. Performance on the QIs is reported as a percentage pass rate.

Results: 170 charts were reviewed (107 early disease and 63 biologic-treated). The most frequent CVD risk factors present at diagnosis (early disease) and biologic start (biologictreated) included hypertension (26\%), obesity (25\%), smoking (21\%) and dyslipidemia $(15 \%)$. Performance on the CVD QIs was highly variable. Areas of low performance $(<10 \%$ pass rates) included documentation of a formal CVD risk assessment, communication to the primary care provider that patients with RA are at increased risk of CVD, body mass index documentation and counselling if overweight, communication to a primary care provider about an elevated blood pressure, and discussion of risks and benefits of anti-inflammatories in patients at CVD risk. Rates of diabetes screening and lipid screening were 67 and $69 \%$ respectively. The area of highest performance was observed for documentation of intent to taper corticosteroid (98-100\% for year 1 and 2 respectively).

Conclusions: Gaps in CVD risk management were found and highlight the need for quality improvements. Key targets for improvement include coordination of CVD care between rheumatology and primary care and communication of increased CVD risk in RA.

\title{
Key indexing terms:
}

Rheumatoid Arthritis

Cardiovascular Diseases

Quality Indicators, Health Care

Primary Prevention

Name of Department and institutions to which the work should be attributed:

1. Department of Medicine, Cumming School of Medicine, University of Calgary

2. Department of Community Health Sciences, Cumming School of Medicine, University of Calgary

3. Arthritis Research Canada 


\section{Funding Support}

Dr. Barber was a PhD candidate during the completion of this work and was supported by a Health Research Clinical Fellowship from Alberta Innovates Health Solutions (AIHS) 2011-2015, a Vanier Canada Graduate Scholarship 2014-2015, as well as a Rheumatology Postgraduate Fellowship funded by UCB Canada, The Canadian Rheumatology (CRA) Association and The Arthritis Society (TAS) from 2011-2013. Dr. Marshall is a Canadian Institutes for Health Research (CIHR) Canada Research Chair in Health Services and Systems Research and the Arthur J.E. Child Chair Rheumatology Research.

Initials, surnames, appointments and highest academic degree of all authors C.E.H. Barber MD, FRCPC, PhD, Assistant Professor, Division of Rheumatology, Department of Medicine, University of Calgary Cumming School of Medicine, J.M. Esdaile MD, MPH, FRCPC, FCAHS, Professor of Medicine, Division of Rheumatology, Department of Medicine, University of British Columbia; Adjunct Professor of Medicine, University of Calgary; Visiting Professor of Medicine, University of Queensland, Australia, Scientific Director, Arthritis Research Canada L.O. Martin MB, MRCPI, FRCPC, Professor, Division of Rheumatology, Department of Medicine, University of Calgary Cumming School of Medicine P. Faris PhD, Adjunct Associate Professor, Department of Community Health Sciences, University of Calgary; Biostatistician, Research Support, Alberta Health Services

C. Barnabe MD, FRCPC, MSc, Assistant Professor, Division of Rheumatology, Department of Medicine, Department of Community Health Sciences, University of Calgary Cumming School of Medicine, Research Scientist, Arthritis Research Canada, ccbarnab@ucalgary.ca

S. Guo BSc, Medical Student, University of Toronto

Elena Lopatina MD, MSc, Department of Community Health Sciences, University of Calgary Cumming School of Medicine

D.A. Marshall MHSA, PhD, Professor, Department of Community Health Sciences, Arthur JE Child Chair in Rheumatology Research, University of Calgary Cumming School of Medicine

\section{Address for Correspondence:}

Claire Barber, MD, FRCPC, PhD

University of Calgary

HRIC 3AA20, 3280, Hospital Dr NW

Calgary, Alberta T2N 4Z6

Tel: 403-220-5903

Fax: 403-210-7367

Email: cehbarbe@ucalgary.ca

Running Footline: Cardiovascular care in RA 


\section{Introduction}

Cardiovascular disease (CVD), including myocardial infarction (MI) and stroke, is more common in patients with rheumatoid arthritis (RA) compared to the general population, with an estimated $48 \%$ increased risk of incident CVD (1). The reasons for this are complex, ultimately reflecting the consequences of inflammation predisposing to endothelial dysfunction (2-6) and premature atherosclerosis (7-9). Despite improvements in the treatment of the inflammatory burden in RA, there continues to be evidence of a widened “mortality gap"(10). One potential contributor is the under-identification and under-treatment of traditional CVD risk factors in RA patients, including smoking, hypertension, obesity and dyslipidemia (11-14), treatment for which results in improved CVD outcomes in the general population.

To guide improvement in the quality of CVD care delivered to RA patients a set of 11 CVD quality indicators (QIs) was developed to assess risk factor screening and management (15). This study reports on the adherence to the CVD QIs for two cohorts of RA patients followed at the University of Calgary Rheumatology Clinics: an early RA (ERA) cohort and a biologics-treated RA cohort. The objective was to determine QI performance over a two-year period, while concurrently assessing the feasibility of capturing the QIs from subspecialty medical records.

\section{Materials \& Methods}

\section{Patient Population}

Two established patient cohorts were used in the study to represent a spectrum of both disease and treatment. 
i) ERA cohort: The cohort was established in 2004 for patients with inflammatory arthritis of recent onset $(<12$ weeks $)(16,17)$. Standardized data are collected at baseline including demographic information (age, sex, ethnicity, duration of symptoms, comorbidities) and medication history. Disease activity, medications and functional status are recorded at each clinic visit. Patients are typically followed for one year in this clinic and then discharged to general rheumatology clinic for follow-up. Follow-up intervals and treatment decisions are at the discretion of the treating rheumatologist $(n=7)$.

ii) The Alberta Biologics Pharmacosurveillance Program (ABioPharm - Calgary). This provincial registry was initiated in 2000 to evaluate the efficacy, safety and costeffectiveness of biologic therapies for patients with RA $(18,19)$. Patients are assessed at baseline initiation or switching of a biologic, 3 months after new therapy initiation, and then yearly or more frequently if required. Data elements collected are the same as for the ERA cohort. For this study, only data for Calgary patients ( $\mathrm{n}=10$ rheumatologists) with a new therapy initiated during the study period were reviewed (as this is the point at which they are entered into the cohort).

\section{Inclusion Criteria}

Charts were selected using a computer-generated random sample of half of the patients from each physician in each cohort and included if the patient met 2010 criteria for RA (20), had no pre-existing diagnosis of CVD including prior MI, stroke, or peripheral vascular disease, and were enrolled in one of the cohorts between January $1^{\text {st }}$ 2010 and August $1^{\text {st }}$ 2014. This start date was selected as it was after the publication of 
international recommendations for CVD risk management for patients with RA (21), bringing heightened attention to the need for management of this comorbidity.

\section{Data sources and abstraction}

Rheumatology charts (electronic and paper) of patients enrolled in either cohort were randomly selected for retrospective review. Three reviewers with medical training abstracted the data independently (one rheumatologist, one cardiologist and one medical student). Standardized data abstraction forms were developed to capture the data elements listed in the next section. The first clinical visit after January $1^{\text {st }} 2010$ was used as a baseline visit and records were reviewed for 2 years.

\section{Sample size calculations}

As routine CVD screening is not currently a mandate for either of these clinics, a worst-case scenario of $50 \%+/-10 \%$ adherence to the QIs was assumed when conducting sample-size calculations. Sample size adjustments were also made to account for physician practice variation using an inter-class correlation coefficient of 0.05 (22) as well as the population sizes of eligible patients in the two cohorts (217 in ERA and 148 in the biologics cohort). Based on these calculations a minimum of 59 biologic charts and 98 ERA would need to be included. To ensure that performance rates were estimated with the desired precision some additional charts were included. Further estimation of confidence intervals was not done for QI performance rates as the sample size ensures a precision $+/-10 \%$ or narrower. 


\section{Clinical variables}

Comorbidities including hypertension, diabetes and dyslipidemia were deemed present at baseline if there was a documented history in the medical record or the patient was on treatment for the condition. Obesity was defined as a body mass index (BMI) $\geq 30 \mathrm{~kg} / \mathrm{m}^{2}$ and overweight as a BMI $25-29.99 \mathrm{~kg} / \mathrm{m}^{2}$. Hypertension was defined as $\geq 140 / 90 \mathrm{mmHg}$ and patients with a lower recommended threshold due to diabetes or chronic kidney disease were excluded from the denominator of hypertension QIs, as other published quality measures better applied to these populations. Medications were captured from each clinic visit.

\section{Cardiac Risk Assessment}

A Stata module (Framingham) (23) was used to calculate a baseline 10-year Framingham risk score (FRS) (24) in eligible patients (ages of 30-74 years and not on a statin at baseline). The FRS was chosen as it is recommended by the Canadian Cardiovascular Society Guidelines (25). Lipid values closest to the baseline visit were used in FRS calculation within a window up to 6-months prior to the baseline visit or one-year post visit, which is more stringent than previous retrospective applications of the score (26). Patients for whom a 10-year FRS score could be calculated were classified into the following levels of risk: $<10 \%$ (low risk), 10 to $19 \%$ (intermediate risk), $\geq 20 \%$ (high risk) (25).

Disease activity was calculated using the Disease Activity Score-28 ESR (DAS28) $(27,28)$ and patients were classified according to disease activity score: remission ( $\leq$ 2.6), low disease activity (2.7- $\leq 3.2)$, moderate disease activity $(3.3-\leq 5.1)$ and high 
disease activity (>5.1). The Health Assessment Questionnaire (HAQ) measured baseline functional status (29).

Analysis

Descriptive statistics were used to summarize baseline clinical features and cardiovascular comorbidities using proportions and means and their standard deviation (sd) or medians (interquartile range, IQR), depending on data normality. Chi-square or Fisher's exact test and t-tests or Wilcoxon-Mann-Whitney tests as appropriate for the data were used to investigate baseline characteristics for patients where a FRS could be computed compared to those in whom it could not.

Adherence to each QI was reported as a percentage and calculated based on the predefined criteria for the numerator, denominator and for exclusion (15) (case record form available upon request). Patients were not eligible for inclusion in the denominator of measures reported at year two if one or more of the following conditions were met. The patient: i) was lost to follow-up; ii) died; iii) was followed less than two years based on their baseline date of study entry; iv) had a CVD event during the course of follow-up. Inter-rater reliability of extraction of data was assessed on 48 randomly selected charts reviewed in duplicate. The percent agreement and Cohen's Kappa (30) were calculated for each QI. Kappa scores were interpreted according to suggested guidelines (31): almost perfect agreement (0.81-0.99), substantial agreement (0.61-0.80), moderate agreement (0.41-0.60), fair agreement (0.21-.40), slight agreement (0.01-0.20). Where disagreement occurred, the chart was re-reviewed by an expert reviewer (a 
rheumatologist who helped develop the QIs) to determine if the QI was met. Stata IC version 13.1 (StataCorp, College Station, Texas) was used for all analyses.

\section{Ethics Approval}

The University of Calgary Health Research Ethics Board approved this project (REB131314). All patients included, consented to inclusion in the cohorts. The study was deemed exempt from re-consenting patients for this specific study by our ethics board.

\section{Results}

\section{Baseline characteristics}

Demographic and clinical characteristics of the included patients are shown in Table 1. There were 170 patients included (63 in the biologics cohort and 107 in the ERA cohort) with a mean age of 55 years and $70 \%$ were female. The median total available follow-up between the baseline date and last clinic visit within the two-year window of evaluation was 607 days and the median number of visits was 6 . 
The RA patients from the biologics cohort had higher disease activity, worse functional status, more erosions and extra-articular manifestations compared to the ERA cohort (see Table 1). Baseline treatments are shown in Table 1. 38\% were on a nonsteroidal anti-inflammatory drugs (NSAIDs), while $22 \%$ received oral prednisone. Over the course of follow-up the disease activity declined to a mean DAS28 of $2.3 \pm 1.2$ and $76 \%$ were in clinical remission.

A total of 7 patients were lost to follow-up, 2 patients could not be assessed for two-year outcomes based on their baseline date of entry in to the cohorts and 2 patients had cardiovascular events. For these reasons, 11 patients in total were not included in the denominators of year 2 QI reporting or in QIs where measurement occurred over a 2-year period.

\section{Cardiovascular risk profile}

The cardiovascular risk profile of patients is shown in Table 2. A quarter of patients had a history of hypertension (26\%), and 90\% these patients were on treatment. A further $14 \%$ had elevated blood pressures $(\geq 140 / 90)$ at their first visit but had no preexisting history of hypertension. A quarter of patients were obese (25\%). Eleven patients had diabetes (7\%) and $26(15 \%)$ had dyslipidemia. Twenty percent of patients were current smokers. A baseline FRS could be calculated for only $44 \%$ of eligible patients $(n=59)$, as the remainder were missing documentation of key variables required for calculation of the score. Where a FRS could be calculated, 34\% were at intermediate or high risk of CVD events. Clinical characteristics including age, sex, number of visits and 
baseline cardiovascular comorbidities were compared between patients for whom an FRS could be calculated to those who did not have enough information to calculate the score and there were no statistically significant differences (data not shown).

\section{Quality Indicator Reporting}

The results of the QI reporting are shown in Table 3. The lowest performance rates were on documentation of a formal CV risk assessment (QI \#2), which was not present on any of the charts during the period of review. Low performance rates $(2 \%)$ were also observed for communication to the primary care practitioner that RA is associated with an increased risk of CVD disease (QI \#1).

High performance rates ( $94 \%$ ) were noted with baseline documentation of smoking status (QI \#3a); however by year two, re-documentation of smoking status in known smokers was lower (42\%). Documentation of smoking cessation advice to current smokers (QI \#3b) was low in both measurement years (17 and 24\% in year 1 and year 2, respectively).

QI\#4 assesses whether a blood pressure has been measured at $80 \%$ or more of clinic visits during each measurement period. For this QI, performance rates for year 1 and 2 were 58 and $66 \%$, respectively. However, when an elevated blood pressure was recorded, recommendations for addressing this were rarely sent back to the primary care provider (5 and 7\% in year 1 and 2, respectively, QI \#5).

Lipid (QI \#6) and glucose screening (QI \#7) were measured over the two-year period of follow-up in 69\% and 67\% of charts, respectively. However, QI \#7b, which captured whether there has been yearly measurement of a fasting glucose or a 
hemoglobin $\mathrm{A} 1 \mathrm{C}$ in individuals with risk factors for diabetes as defined by specific criteria published in the original QI specifications and outlined in Table 3, was slightly lower ( $48 \%$ in year 1 and $54 \%$ in year 2$)$.

Yearly discussion of physical activity recommendations (QI \#8) had poor performance in year $1(33 \%)$ that declined in year $2(15 \%)$. Similarly BMI screening rates were low (QI \#9a, 4-6\%). Although the rates of calculation of BMIs were low, height and weight were available on the majority of patients and were used to estimate the denominator for QI \#9b, which captures lifestyle counseling to overweight and obese patients. Performance on this part of the indicator was also low (5-9\%).

Finally, with regard to the two treatment QIs, performance on QI \#10 (minimizing corticosteroid usage) was high (98-100\% depending on the measurement year). In contrast, communication regarding risks of NSAIDs in patients at intermediate or high risk of CVD events was low, although the denominator was small as many patients were excluded as the level of risk was uncertain or they were not clearly on NSAIDs during the measurement year.

While the mandate of this study was not to compare the QI performance rates between cohorts, the majority of performance rates were similar between the two cohorts with two exceptions. The rate of blood pressure screening was significantly lower in year 1 in the biologics cohort compared to the ERA cohort $(33 \%$ versus $72 \%, \mathrm{p}<0.001)$ and the rates of exercise counselling were higher in the ERA cohort in year 1 compared to the biologics cohort ( $41 \%$ versus $19 \%, \mathrm{p}=0.003)$.

Inter-rater reliability of $Q I S$ 
Inter-rater reliability was calculated using Cohen's Kappa for each QI in 48 charts (Table 4). Overall there was moderate to perfect agreement in 11 out of 13 measures where a Kappa score could be calculated $(85 \%)$ with some variation in scores by year noted. Because of the known properties of Kappa, whereby QIs with a high or low performance can be accompanied by a high agreement but a low Kappa score (32), two Kappa scores were misleading (QI \#1 and \#2b, Table 4).

\section{Discussion}

This study systematically addresses performance on recently developed CVD QIs for RA (15). Consistent with other reports (13), our patients have a high burden of cardiovascular risk factors and would benefit from improvements in screening and management of CVD risk to address the performance gaps identified.

There is substantial debate in the rheumatology community about the role rheumatologists should play in evaluating and treating CVD risk factors (33). Proponents of the rheumatologists taking a role in management of CVD risk cite deficits in primary care screening management of CVD risk factors in RA $(12,34-36)$. Indeed prospective and systematic evaluation of RA patients in a number of studies has uncovered previously unidentified and untreated risk factors including hypertension, dyslipidemia and hyperglycemia $(13,14)$. Conversely, primary care physicians are expert in CVD screening in the general population and some argue that screening should occur in primary care. Although to accomplish better primary care screening for CVD risk in RA, primary care education and improved coordination of care with the rheumatologist are likely necessary to achieve optimal processes and outcomes $(33,37)$. 
Unfortunately, a major critique of systematic assessment for CVD risk factors is that it can be time consuming (14). The CVD QIs evaluated in this study were developed and worded to enhance CVD care in RA without placing the entire burden of care on the rheumatologist (15). For example, many of the QIs are framed in such a way that captures whether another physician, e.g., the primary care provider, was reminded to monitor the patients' cardiovascular risk factors which shares the burden of care and removes it somewhat from the rheumatologist, who may be less familiar with CVD treatment guidelines. Unfortunately, many of the communication QIs had poor adherence. Also, CVD preventive care such as smoking cessation advice, exercise review and lifestyle counseling may occur but be poorly documented. Failure to document such discussions is an opportunity for quality improvement not only in CVD risk screening but also in coordination of care.

Although the main objective of the study was not to compare the performance of the QIs between the cohorts, two significant differences were observed. Performance on QI \#4 (blood pressure measurement) was higher in the ERA cohort compared to the biologics cohort and this may reflect differences in who was collecting baseline data in the cohort charts (i.e., there were more nursing assessments in the ABioPharm clinics were the biologics patients were seen and it is possible that routine blood pressure estimation was done less frequently for these visits than a typical rheumatologist visit). Exercise (QI \#8) was more frequently discussed in the ERA cohort in year 1 and this likely reflected the practice of referring new patients for a physiotherapy assessment and exercise counselling in this cohort. 
The study demonstrated that although cardiovascular risk estimation was not documented in this study (QI \#2a), 69\% of the time there was a lipid profile done within 2 years of baseline (QI \#6) and often there was available information for calculation a risk score, which is substantially higher than in other reports (11). Also of note for QI \#9a, although BMI was actually calculated on very few charts, both height and weight were captured on all charts at baseline but this did not meet criteria for the QI numerator. Failure to document BMI and CVD risk assessments may be lost opportunities for identification of risk and further work will need to be done to examine barriers to risk estimation and CVD screening in the rheumatology clinic. Alternatively, an evaluation of primary care practices of CVD risk estimation and treatment in RA could be done to better understand this suspected gap in care as the study did not have access to primary care records and it is unclear to what degree risk assessment and treatment is occurring at this level.

Limitations of this study are recognized. Firstly, although the QIs could be measured using information extracted from patient charts, it should be highlighted that the process was time consuming and resource intensive, and may not be a practical approach in routine practice. Secondly, this study included patients from research cohorts and it is anticipated that QI adherence could be higher in this setting due to more standardized delivery of care and/or collection of data. Additionally, in the original specification of some QIs, the interval for evaluation was up to 5 years. Unfortunately there was not enough follow-up available on the patients from the time when CV guidelines were first recommended for RA (21). It should also be noted that the estimate of patients with dyslipidemia included individuals with a diagnosis of dyslipidemia, 
abnormal lipid tests or on statin therapy. This estimate therefore may have included patients with diabetes put on statin therapies prophylactically, without a diagnosis of dyslipidemia. Given the numbers of patients with concomitant diabetes and dyslipidemia was low $(\mathrm{n}=6)$, this likely did not substantially impact the result. Finally, there was no control population of patients without RA given that the QIs were specifically designed for this population, and it is possible that similar results could be found in patients with other chronic diseases.

As this was the first time the QIs have been studied, the inter-rater reliability was assessed as it is a key facet of QI testing. Although $85 \%$ of all QIs had moderate to perfect agreement based on Kappa score, not all QIs met this threshold. This did not substantially impact the final results as any disagreements between reviewers were verified in the chart to obtain the most accurate data capture.

During the assessment of inter-rater reliability, there were three types of potential challenges with applying the QIs and potential solutions are identified below:

1. Issues with correctly determining eligibility for a QI: Accurate calculation of dates is required to ascertain whether a patient was eligible for a QI. Errors may also have occurred where criteria for denominator inclusion were complex. For example, QI\#11 where performance was based on two or more factors, i.e., where patients in the denominator had to be on NSAIDs AND had to have intermediate or high risk for CVD during the period of evaluation. Electronic capture of the QIs with automatic calculation and checking of dates and eligibility criteria would rectify this problem.

2. Difficulty interpreting QI wording to ascertain inclusion in the numerator: this was most problematic for QI \#8 (Exercise). Although specific criteria for meeting this 
were listed in the case record form, there were different interpretations of eligibility by the reviewers. A modification to the inclusion criteria for the QI is therefore suggested, which requires provider documentation that the patient meets defined exercise targets. According to Canadian guidelines (38), this would be 150 minutes of moderate-intensity activity per week in bouts of $\geq 10$ minutes.

3. Complexity of chart review due to multiple sources of data: Some pieces of information, e.g., smoking status for the biologic patients, were more reliably captured in the study chart than the clinical chart. This led to poor inter-rater reliability in some cases depending on the thoroughness and/or interpretation of data for review in these multiple sources. Again, a single data source, perhaps an electronic medical record with better medication capture, would be helpful in documenting adherence to many of the QIs.

In summary, this study demonstrates that even in a highly controlled setting where standardized data collection is completed for reporting on clinical cohorts, there is room for improvement in CVD screening and care in RA. Gaps in CVD risk management were found and highlight the need for quality improvements. Key targets for improvement include coordination of CVD care between rheumatology and primary care and communication of increased CVD risk in RA. 


\section{Acknowledgements}

The authors would like to acknowledge the contribution of Lauren Jewett for the construction of a Microsoft ACCESS database where the data was entered before exporting for analysis. 


\section{References}

1. Avina-Zubieta JA, Thomas J, Sadatsafavi M, Lehman AJ, Lacaille D. Risk of incident cardiovascular events in patients with rheumatoid arthritis: a meta-analysis of observational studies. Ann Rheum Dis 2012;71:1524-9.

2. de Groot L, Hinkema H, Westra J, Smit AJ, Kallenberg CG, Bijl M, et al. Advanced glycation endproducts are increased in rheumatoid arthritis patients with controlled disease. Arthritis Res Ther 2011;13:R205.

3. de Groot L, Jager NA, Westra J, Smit AJ, Kallenberg CG, Posthumus MD, et al. Does reduction of disease activity improve early markers of cardiovascular disease in newly diagnosed rheumatoid arthritis patients? Rheumatology (Oxford) 2015;54:125761.

4. Westra J, de Groot L, Plaxton SL, Brouwer E, Posthumus MD, Kallenberg CG, et al. Angiopoietin-2 is highly correlated with inflammation and disease activity in recentonset rheumatoid arthritis and could be predictive for cardiovascular disease. Rheumatology (Oxford) 2011;50:665-73.

5. Dessein PH, Joffe BI, Singh S. Biomarkers of endothelial dysfunction, cardiovascular risk factors and atherosclerosis in rheumatoid arthritis. Arthritis Res Ther 2005;7:R634-43.

6. Santos MJ, Carmona-Fernandes D, Canhao H, Canas da Silva J, Fonseca JE, Gil V. Early vascular alterations in SLE and RA patients--a step towards understanding the associated cardiovascular risk. PloS one 2012;7:e44668.

7. Mason JC, Libby P. Cardiovascular disease in patients with chronic inflammation: mechanisms underlying premature cardiovascular events in rheumatologic conditions. Eur Heart J 2015;36:482-9c.

8. Corrales A, Dessein PH, Tsang L, Pina T, Blanco R, Gonzalez-Juanatey C, et al. Carotid artery plaque in women with rheumatoid arthritis and low estimated cardiovascular disease risk: a cross-sectional study. Arthritis Res Ther 2015;17:55.

9. Gabriel SE, Crowson CS. Risk factors for cardiovascular disease in rheumatoid arthritis. Curr Opin Rheumatol 2012;24:171-6.

10. Widdifield J, Bernatsky S, Paterson JM, Tomlinson G, Tu K, Kuriya B, et al. Trends in Excess Mortality Among Patients With Rheumatoid Arthritis in Ontario, Canada. Arthritis Care Res (Hoboken) 2015;67:1047-53.

11. Keeling SO, Teo M, Fung D. Lack of cardiovascular risk assessment in inflammatory arthritis and systemic lupus erythematosus patients at a tertiary care center. Clin Rheumatol 2011;30:1311-7.

12. Desai SS, Myles JD, Kaplan MJ. Suboptimal cardiovascular risk factor identification and management in patients with rheumatoid arthritis: a cohort analysis. Arthritis Res Ther 2012;14:R270.

13. Dougados M, Soubrier M, Antunez A, Balint P, Balsa A, Buch MH, et al. Prevalence of comorbidities in rheumatoid arthritis and evaluation of their monitoring: results of an international, cross-sectional study (COMORA). Ann Rheum Dis 2014;73:62-8. 
14. Gossec L, Salejan F, Nataf H, Nguyen M, Gaud-Listrat V, Hudry C, et al. Challenges of cardiovascular risk assessment in the routine rheumatology outpatient setting: an observational study of 110 rheumatoid arthritis patients. Arthritis Care Res (Hoboken) 2013;65:712-7.

15. Barber CE, Marshall DA, Alvarez N, Mancini GB, Lacaille D, Keeling S, et al. Development of cardiovascular quality indicators for rheumatoid arthritis: results from an international expert panel using a novel online process. J Rheumatol 2015;42:1548-55.

16. Dissanayake T, Barr SG, Panney C, Morris G, Mosher DP, Martin L. Efficacy of methotrexate monotherapy compared to combination therapy with methotrexate and hydroxychloroquine in the treatment of early rheumatoid arthritis after 12 months of treatment [abstract]. J Rheumatol 2014;41:1493-4.

17. Dissanayake T, Barr SG, Penney C, Morris G, Mosher D, L M. Efficacy of methotrexate monotherapy compared to methotrexate and hydroxychloroquine in the treatment of early rheumatoid arthritis [abstract]. Ann Rheum Dis 2011;70:607.

18. Barnabe C, Homik J, Barr SG, Martin L, Maksymowych WP. The effect of different remission definitions on identification of predictors of both point and sustained remission in rheumatoid arthritis treated with anti-TNF therapy. J Rheumatol 2014;41:1607-13.

19. Barr SG, Martin L, Chung C, Maksymowych WP. Mandatory pharmacosurveillance--a Canadian model for access to therapy and research. Clin Exp Rheumatol 2004;22:S39-43.

20. Aletaha D, Neogi T, Silman AJ, Funovits J, Felson DT, Bingham CO, 3rd, et al. 2010 Rheumatoid arthritis classification criteria: an American College of Rheumatology/European League Against Rheumatism collaborative initiative. Arthritis Rheum 2010;62:2569-81.

21. Peters MJL, Symmons DPM, McCarey D, Dijkmans BAC, Nicola P, Kvien TK, et al. EULAR evidence-based recommendations for cardiovascular risk management in patients with rheumatoid arthritis and other forms of inflammatory arthritis. Ann Rheum Dis 2010;69:325-31.

22. Parker DR, Evangelou E, Eaton CB. Intraclass correlation coefficients for cluster randomized trials in primary care: the cholesterol education and research trial (CEART). Contemp Clin Trials 2005;26:260-7.

23. Linden A. Framingham: Stata module for calculating the Framingham 10-year coronary vascular disease risk prediction. 2015 [cited 2016 January 16]; Available from: https://ideas.repec.org/c/boc/bocode/s457997.html\#author

24. D'Agostino RB, Sr., Vasan RS, Pencina MJ, Wolf PA, Cobain M, Massaro JM, et al. General cardiovascular risk profile for use in primary care: the Framingham Heart Study. Circulation 2008; 117:743-53.

25. Anderson TJ, Gregoire J, Hegele RA, Couture P, Mancini GBJ, McPherson R, et al. 2012 update of the Canadian Cardiovascular Society guidelines for the diagnosis and treatment of dyslipidemia for the prevention of cardiovascular disease in the adult. Can J Cardiol 2013;29:151-67.

26. Crowson CS, Matteson EL, Roger VL, Therneau TM, Gabriel SE. Usefulness of risk scores to estimate the risk of cardiovascular disease in patients with rheumatoid arthritis. Am J Cardiol 2012;110:420-4. 
27. DAS 28-score website. 2016 [cited 2016 January 16]; Available from: http://www.das-score.nl/das28/en/

28. Prevoo ML, van 't Hof MA, Kuper HH, van Leeuwen MA, van de Putte LB, van Riel PL. Modified disease activity scores that include twenty-eight-joint counts. Development and validation in a prospective longitudinal study of patients with rheumatoid arthritis. Arthritis Rheum 1995;38:44-8.

29. Bruce B, Fries JF. The Health Assessment Questionnaire (HAQ). Clin Exp Rheumatol 2005;23:S14-8.

30. Cohen J. A coefficient of agreement for nominal scales. Educ Psychol Meas 1960;20:37-46.

31. Oleckno WA. Epidemiology, Concepts and Methods. Long Grove, IL: Waveland Press, Inc.; 2008.

32. Cicchetti DV, Feinstein AR. High agreement but low kappa: II. Resolving the paradoxes. J Clin Epidemiol 1990;43:551-8.

33. Solomon DH, Peters MJ, Nurmohamed MT, Dixon W. Unresolved questions in rheumatology: motion for debate: the data support evidence-based management recommendations for cardiovascular disease in rheumatoid arthritis. Arthritis Rheum 2013;65:1675-83.

34. Bartels CM, Kind AJH, Everett C, Mell M, McBride P, Smith M. Low frequency of primary lipid screening among medicare patients with rheumatoid arthritis. Arthritis Rheum 2011;63:1221-30.

35. Bartels CM, Kind AJ, Thorpe CT, Everett CM, Cook RJ, McBride PE, et al. Lipid testing in patients with rheumatoid arthritis and key cardiovascular-related comorbidities: a medicare analysis. Semin Arthritis Rheum 2012;42:9-16.

36. Bartels CM, Johnson H, Voelker K, Thorpe C, McBride P, Jacobs EA, et al. Impact of rheumatoid arthritis on receiving a diagnosis of hypertension among patients with regular primary care. Arthritis Care Res (Hoboken) 2014;66:1281-8.

37. The Royal Australian College of General Practitioners (RACGP). Clinical guideline for the diagnosis and management of early rheumatoid arthritis. 2009 [cited 2013 June 17]; Available from:

http://www.racgp.org.au/download/documents/Guidelines/Musculoskeletal/racgp ra gui deline.pdf

38. Canadian Society for Exercise Physiology. Canadian physical activity guidelines for adults 18-64 years. Canadian Society for Exercise Physiology; [cited 2015 September 12]; Available from: http://www.csep.ca/en/guidelines/get-the-guidelines 
Table 1. Baseline clinical characteristics for patients in the biologics and ERA cohorts included in the quality indicator review

\begin{tabular}{|c|c|c|c|}
\hline & Overall $(n=170 *)$ & Biologics $\left(n=63^{*}\right)$ & $\operatorname{ERA}(n=107 *)$ \\
\hline Mean age (sd) & $\begin{array}{c}54.6(13.6) \\
\text { Range } 22 \text { to } 89\end{array}$ & $\begin{array}{c}57.5(15.1) \\
\text { Range } 25 \text { to } 89\end{array}$ & $\begin{array}{c}52.9(12.4) \\
\text { Range } 22 \text { to } 89\end{array}$ \\
\hline Female Sex & $119(70 \%)$ & $51(81 \%)$ & $68(64 \%)$ \\
\hline Ethnicity & $\begin{array}{l}82(48 \%) \text { Caucasian } \\
69(41 \%) \text { not stated }\end{array}$ & $\begin{array}{l}42(67 \%) \text { Caucasian } \\
13(21 \%) \text { not stated }\end{array}$ & $\begin{array}{l}40(37 \%) \text { Caucasian } \\
56(52 \%) \text { not stated }\end{array}$ \\
\hline $\begin{array}{l}\text { Duration of disease } \\
\text { since diagnosis in } \\
\text { years at baseline visit }\end{array}$ & $\begin{array}{c}\text { See biologics as N/A for } \\
\text { ERA }\end{array}$ & $\begin{array}{c}\text { Median } 5.5 \text { years } \\
(\mathrm{IQR} 2,15)(\mathrm{N}=62)\end{array}$ & N/A \\
\hline $\begin{array}{l}\text { Duration between } \\
\text { symptom onset and } \\
\text { diagnosis }\end{array}$ & $\begin{array}{c}\text { Median } 6.1 \text { months } \\
\text { (IQR 3.3, } 12.2 \text { months) } \\
(\mathrm{n}=159)\end{array}$ & $\begin{array}{c}\text { Median } 6.7 \text { months } \\
\text { (IQR 3.0, } 21.8 \\
\text { months) }(\mathrm{n}=52)\end{array}$ & $\begin{array}{c}\text { Median } 6.1 \text { months } \\
\text { (IQR 3.5, } 11.6 \\
\text { months) }(\mathrm{n}=107)\end{array}$ \\
\hline $\begin{array}{l}\text { Duration of follow- } \\
\text { up** }\end{array}$ & $\begin{array}{c}\text { Median } 607 \text { days (IQR } \\
482,678 \text { days) }\end{array}$ & $\begin{array}{c}\text { Median } 616 \text { days } \\
\text { (IQR 524, } 685 \text { days) }\end{array}$ & $\begin{array}{c}\text { Median } 606 \\
\text { (IQR 472, } 674 \text { days) }\end{array}$ \\
\hline $\begin{array}{l}\text { Rheumatoid factor } \\
\text { positive }\end{array}$ & $125(74 \%)$ & $45(71 \%)$ & $80(75 \%)$ \\
\hline Anti-CCP positive & $139(82 \%)(\mathrm{N}=166)$ & $47(75 \%)(\mathrm{N}=61)$ & $92(86 \%)(\mathrm{N}=105)$ \\
\hline Nodules & $20(12 \%)$ & $14(22 \%)$ & $6(6 \%)$ \\
\hline $\begin{array}{l}\text { Erosions on baseline } \\
\text { radiographs }\end{array}$ & $59(35 \%)(\mathrm{N}=165)$ & $40(63 \%)(\mathrm{N}=62)$ & $19(18 \%)(\mathrm{N}=103)$ \\
\hline $\begin{array}{l}\text { Extra-articular RA } \\
\text { manifestations } * * *\end{array}$ & $11(7 \%)$ & $8(13 \%)$ & $3(3 \%)$ \\
\hline $\begin{array}{l}\text { Mean Baseline HAQ } \\
\text { score (sd) }\end{array}$ & $1.35(0.7)(\mathrm{N}=165)$ & $1.7(0.6)(\mathrm{N}=63)$ & $1.13(0.7)(\mathrm{N}=102)$ \\
\hline $\begin{array}{l}\text { Mean Baseline } \\
\text { DAS28 } \\
\text { (SD) }\end{array}$ & $5.46(1.37)(\mathrm{N}=156)$ & $5.76(1.04)(\mathrm{N}=59)$ & $5.28(1.51)(\mathrm{N}=97)$ \\
\hline $\begin{array}{l}\text { Moderate Disease } \\
\text { Activity (DAS28 }>3.2 \\
\text { to } \leq 5.1)\end{array}$ & $49(35 \%)$ & $17(29 \%)$ & $32(33 \%)$ \\
\hline $\begin{array}{l}\text { High Disease Activity } \\
(\text { DAS28 }>5.1)\end{array}$ & $97(62 \%)$ & $42(71 \%)$ & $55(57 \%)$ \\
\hline \multicolumn{4}{|c|}{ Baseline RA treatment (at end of the first visit) } \\
\hline $\begin{array}{l}\text { Any baseline } \\
\text { DMARD }\end{array}$ & $153(90 \%)$ & $53(84 \%)$ & $100(93 \%)$ \\
\hline Plaquenil & $94(55 \%)$ & $21(33 \%)$ & $73(68 \%)$ \\
\hline Methotrexate & $124(73 \%)$ & $37(59 \%)$ & $87(81 \%)$ \\
\hline Leflunomide & $10(6 \%)$ & $10(16 \%)$ & 0 \\
\hline Sulfasalazine & $12(7 \%)$ & $8(13 \%)$ & $4(13 \%)$ \\
\hline Combination & $80(47 \%)$ & $18(29 \%)$ & $62(58 \%)$ \\
\hline
\end{tabular}




\begin{tabular}{|c|c|c|c|}
\hline $\begin{array}{l}\text { DMARD therapy (any } \\
\text { combination) }\end{array}$ & & & \\
\hline $\begin{array}{l}\text { Methotrexate }+ \\
\text { Plaquenil }\end{array}$ & $66(39 \%)$ & $8(13 \%)$ & $58(54 \%)$ \\
\hline Biologics & $62(37 \%)$ & $62(98 \%)$ & 0 \\
\hline $\begin{array}{l}\text { NSAID (other than } \\
\text { ASA at first visit) }\end{array}$ & $64(38 \%)$ & $30(48 \%)$ & $34(32 \%)$ \\
\hline Prednisone & $37(22 \%)$ & $21(33 \%)$ & $16(15 \%)$ \\
\hline $\begin{array}{l}\text { Intra-muscular } \\
\text { glucocorticoids }\end{array}$ & $62(37 \%)$ & $7(11 \%)$ & $55(51 \%)$ \\
\hline $\begin{array}{l}\text { Intra-articular } \\
\text { glucocorticoids }\end{array}$ & $12(7 \%)$ & $3(5 \%)$ & $9(8 \%)$ \\
\hline \multicolumn{4}{|c|}{ Number of follow-ups over study \& Disease activity at end of follow-up } \\
\hline $\begin{array}{l}\text { Mean number of } \\
\text { follow-up visits over } \\
2 \text { year }(\mathrm{sd})\end{array}$ & Mean 6.1 (1.9) & Mean $5.9(1.8)$ & Mean $6.3(2.0)$ \\
\hline $\begin{array}{l}\text { DAS-28 at end of } \\
\text { follow-up } \\
\text { (sd) }\end{array}$ & $2.3(1.2)(\mathrm{N}=108)$ & $2.9(1.3)(\mathrm{N}=38)$ & $2.1(1.1)(\mathrm{N}=70)$ \\
\hline $\begin{array}{l}\text { Remission or Low } \\
\text { Disease Activity } \\
(\mathrm{DAS} \leq 3.2)\end{array}$ & $82(76 \%)$ & $23(61 \%)$ & $59(84 \%)$ \\
\hline $\begin{array}{l}\text { CVD events over the } \\
\text { course of follow-up }\end{array}$ & $\begin{array}{l}2 \text { patients (two MIs, one } \\
\text { aneurysm repair) }\end{array}$ & 0 & $\begin{array}{l}2 \text { (two MIs, one } \\
\text { aneurysm repair) }\end{array}$ \\
\hline
\end{tabular}

* The numbers of patients included is as described at the top of the table, unless otherwise specified.

**Duration of follow-up between baseline visit and last follow-up date within 2 years (in ERA clinic this is calculated from date of diagnosis of RA and in Biologics from biologics clinic date where a switch or new start to a biologic was made)

***Other Extra-articular manifestations included the following: interstitial lung disease, pleural disease, RA vasculitis (rheumatoid nodules not counted here)

Abbreviations: cardiovascular disease (CVD), Disease activity score-28 (DAS-28), Disease Modifying Anti-rheumatic Drug (DMARD), Early Rheumatoid Arthritis (ERA), Health Assessment Questionnaire (HAQ), interquartile range (IQR), Rheumatoid Arthritis (RA), Standard Deviation (sd) 
Table 2. Cardiovascular risk profile \& treatment characteristics of patients with rheumatoid arthritis in the biologics and ERA cohorts

\begin{tabular}{|c|c|c|c|}
\hline & $\begin{array}{l}\text { Overall } \\
(n=170)\end{array}$ & $\begin{array}{c}\text { Biologics } \\
(n=63)\end{array}$ & ERA $(n=107)$ \\
\hline Hypertension & $44(26 \%)$ & $23(37 \%)$ & $21(20 \%)$ \\
\hline $\begin{array}{l}\text { Blood pressure } \geq 140 / 90 \text { at first } \\
\text { visit and no prior diagnosis of } \\
\text { hypertension }\end{array}$ & $23(14 \%)$ & $4(6 \%)$ & $19(18 \%)$ \\
\hline Diabetes & $11(7 \%)$ & $4(6 \%)$ & $7(7 \%)$ \\
\hline Dyslipidemia* & $26(15 \%)$ & $10(16 \%)$ & $16(15 \%)$ \\
\hline Obesity (BMI $\geq 30)$ & $43(25 \%)$ & $14(22 \%)$ & $29(27 \%)$ \\
\hline Mean BMI (sd) & $27.3(4.9)$ & $26.7(5.1)$ & $27.5(4.9)$ \\
\hline $\begin{array}{l}\text { Family history of Cardiovascular } \\
\text { disease }\end{array}$ & $4(2 \%)$ & $1(2 \%)$ & $3(3 \%)$ \\
\hline $\begin{array}{l}\text { Missing information on family } \\
\text { history }\end{array}$ & $58(34 \%)$ & $41(65 \%)$ & $17(16 \%)$ \\
\hline Current smoker & $35(21 \%)$ & $8(13 \%)$ & $27(25 \%)$ \\
\hline Ex-smoker & $56(33 \%)$ & $26(41 \%)$ & $30(28 \%)$ \\
\hline Non-smoker & $69(41 \%)$ & $25(40 \%)$ & $44(41 \%)$ \\
\hline Missing smoking data & $10(6 \%)$ & $4(6 \%)$ & $6(6 \%)$ \\
\hline \multicolumn{4}{|c|}{ *Baseline Framingham Risk score (FRS) $\mathbf{N}=59$ FRS calculated } \\
\hline FRS low & $39(66 \%)$ & $6(75 \%)$ & $33(65 \%)$ \\
\hline FRS intermediate & $13(22 \%)$ & $2(25 \%)$ & $11(22 \%)$ \\
\hline FRS high & $7(11 \%)$ & $0(0 \%)$ & $7(14 \%)$ \\
\hline \multicolumn{4}{|c|}{ FRS could not be calculated but patients were eligible for FRS estimation $N=134$} \\
\hline FRS could not be calculated & $75(56 \%)$ & $39(83 \%)$ & $36(41 \%)$ \\
\hline \multicolumn{4}{|c|}{ Baseline Cardiovascular Risk Factor Treatment (at end of first visit) } \\
\hline Aspirin & $19(11 \%)$ & $9(14 \%)$ & $10(10 \%)$ \\
\hline Statin** & $\begin{array}{l}19(11 \%) \\
(\mathrm{N}=168)\end{array}$ & $\begin{array}{l}7(11 \%) \\
(\mathrm{N}=62) \\
\end{array}$ & $\begin{array}{c}12(11 \%) \\
(\mathrm{N}=12)\end{array}$ \\
\hline Anti-hypertensive agents (any) & $40(24 \%)$ & $21(33 \%)$ & $19(18 \%)$ \\
\hline
\end{tabular}

* Baseline Framingham Risk Score was calculated with baseline variables at first visit using lipid values from up to 6months prior to first visit and 1 year after.

** 2 patients had major missing and/or conflicting information in the chart and statin use and dyslipidemia history could not be determined Abbreviations: Body Mass Index (BMI), Early Rheumatoid Arthritis (ERA), Framingham Risk Score (FRS), Standard Deviation (sd) 
Table 3. Adherence to 11 Cardiovascular Quality Indicators in 2 cohorts*

\begin{tabular}{|c|c|c|c|c|c|c|}
\hline Quality Indicator & & Total & \multicolumn{2}{|c|}{ Biologics } & \multicolumn{2}{|c|}{ ERA } \\
\hline $\begin{array}{l}\text { 1. Communication of increased CV risk in RA: IF a } \\
\text { patient has rheumatoid arthritis, THEN the treating } \\
\text { rheumatologist should communicate to the primary care } \\
\text { physician, at least once within the last } 2 \text { years that patients } \\
\text { with RA have an increased cardiovascular risk. }\end{array}$ & \multicolumn{2}{|c|}{$3 / 158(2 \%)$} & \multicolumn{2}{|c|}{$0 / 62(0 \%)$} & \multicolumn{2}{|c|}{$3 / 96(3 \%)$} \\
\hline $\begin{array}{l}\text { 2. CV risk assessment: a. IF a patient has rheumatoid } \\
\text { arthritis THEN a formal cardiovascular risk assessment } \\
\text { according to national guidelines should be done at least once } \\
\text { in the first two years after evaluation by a rheumatologist }\end{array}$ & \multicolumn{2}{|c|}{$0 / 150(0 \%)$} & \multicolumn{2}{|c|}{$0 / 58(0 \%)$} & \multicolumn{2}{|c|}{$0 / 92(0 \%)$} \\
\hline $\begin{array}{l}\text { 2b. If initial assessment suggests intermediate or high-risk, } \\
\text { THEN treatment of risk factors according to national } \\
\text { guidelines should be recommended. }\end{array}$ & \multicolumn{6}{|c|}{$\begin{array}{l}\text { There were no patients with a risk assessment, therefore both the } \\
\text { numerator and denominator for this QI was } 0 .\end{array}$} \\
\hline \multirow{2}{*}{$\begin{array}{l}\text { 3a.Smoking status and cessation counseling: IF a patient } \\
\text { has rheumatoid arthritis THEN their smoking and tobacco } \\
\text { use status should be documented at least once in the last year }\end{array}$} & Y1 & Y2 & Y1 & Y2 & Y1 & $\mathbf{Y 2}$ \\
\hline & $\begin{array}{c}160 / 170 \\
(94 \%) \\
\end{array}$ & $\begin{array}{c}16 / 38^{* *} \\
(42 \%) \\
\end{array}$ & $\begin{array}{l}59 / 63 \\
(94 \%) \\
\end{array}$ & $\begin{array}{l}5 / 10 * * \\
(50 \%) \\
\end{array}$ & $\begin{array}{c}101 / 107 \\
(94 \%)\end{array}$ & $\begin{array}{c}11 / 28^{* *} \\
(39 \%)\end{array}$ \\
\hline $\begin{array}{l}\text { 3b. IF they are current smokers or tobacco users they should } \\
\text { be counseled to stop smoking. }\end{array}$ & $\begin{array}{c}6 / 35 \\
(17 \%)\end{array}$ & $\begin{array}{l}4 / 17 \\
(24 \%)\end{array}$ & $\begin{array}{c}3 / 8 \\
(38 \%)\end{array}$ & $\begin{array}{c}1 / 4 \\
(25 \%)\end{array}$ & $\begin{array}{c}3 / 27 \\
(11 \%)\end{array}$ & $\begin{array}{c}3 / 13 \\
(23 \%)\end{array}$ \\
\hline $\begin{array}{l}\text { 4. Screening for hypertension: IF a patient has rheumatoid } \\
\text { arthritis THEN their blood pressure should be measured and } \\
\text { documented in the medical record at } \geq 80 \% \text { of clinic visits. }\end{array}$ & $\begin{array}{c}98 / 170 \\
(58 \%)\end{array}$ & $\begin{array}{l}105 / 159 \\
(66 \%)\end{array}$ & $\begin{array}{l}21 / 63 \\
(33 \%)\end{array}$ & $\begin{array}{l}45 / 62 \\
(73 \%)\end{array}$ & $\begin{array}{l}77 / 107 \\
(72 \%)\end{array}$ & $\begin{array}{l}60 / 97 \\
(62 \%)\end{array}$ \\
\hline $\begin{array}{l}\text { 5. Communication to PCP about a documented high } \\
\text { blood pressure: IF a patient has rheumatoid arthritis AND } \\
\text { has a blood pressure measured during a rheumatology clinic } \\
\text { visit that is elevated (systolic blood pressure } \geq 140 \mathrm{mmHg} \\
\text { and/or diastolic blood pressure } \geq 90 \mathrm{mmHg} \text { ) THEN the }\end{array}$ & $\begin{array}{l}5 / 76 \\
(7 \%)\end{array}$ & $\begin{array}{l}3 / 59 \\
(5 \%)\end{array}$ & $\begin{array}{l}3 / 24 \\
(4 \%)\end{array}$ & $\begin{array}{l}1 / 19 \\
(5 \%)\end{array}$ & $\begin{array}{l}2 / 52 \\
(4 \%)\end{array}$ & $\begin{array}{l}2 / 40 \\
(5 \%)\end{array}$ \\
\hline
\end{tabular}




\begin{tabular}{|c|c|c|c|c|c|c|}
\hline \multicolumn{7}{|l|}{$\begin{array}{l}\text { rheumatologist should recommend that it be repeated and } \\
\text { treatment initiated or adjusted if indicated. }\end{array}$} \\
\hline $\begin{array}{l}\text { 6. Measurement of a lipid profile: IF a patient has } \\
\text { rheumatoid arthritis THEN a lipid profile should be done at } \\
\text { least once in the first two years after evaluation by a } \\
\text { rheumatologist }\end{array}$ & \multicolumn{2}{|c|}{$110 / 159(69 \%)$} & \multicolumn{2}{|c|}{$37 / 62(59 \%)$} & \multicolumn{2}{|c|}{$73 / 97(75 \%)$} \\
\hline $\begin{array}{l}\text { 7. Screening for diabetes: IF a patient has rheumatoid } \\
\text { arthritis THEN diabetes should be screened for as part of a } \\
\text { cardiovascular risk assessment at least once within the first } 2 \\
\text { years of evaluation by a rheumatologist. } * * *\end{array}$ & \multicolumn{2}{|c|}{$100 / 149(67 \%)$} & \multicolumn{2}{|c|}{$34 / 58(59 \%)$} & \multicolumn{2}{|c|}{$66 / 91(73 \%)$} \\
\hline \multirow{2}{*}{ 7b. Yearly in intermediate or high-risk patients. $* * * *$} & Y1 & Y2 & Y1 & Y2 & Y1 & Y2 \\
\hline & $\begin{array}{l}72 / 132 \\
(54 \%)\end{array}$ & $\begin{array}{l}57 / 119 \\
(48 \%)\end{array}$ & $\begin{array}{l}21 / 50 \\
(42 \%)\end{array}$ & $\begin{array}{l}20 / 44 \\
(45 \%)\end{array}$ & $\begin{array}{l}51 / 82 \\
(62 \%)\end{array}$ & $\begin{array}{l}37 / 75 \\
(49 \%)\end{array}$ \\
\hline $\begin{array}{l}\text { 8. Exercise: IF a patient has rheumatoid arthritis THEN } \\
\text { physical activity goals should be discussed with their } \\
\text { rheumatologist at least once yearly. }\end{array}$ & $\begin{array}{l}55 / 168 \\
(33 \%)\end{array}$ & $\begin{array}{l}24 / 158 \\
(15 \%)\end{array}$ & $\begin{array}{l}12 / 63 \\
(19 \%)\end{array}$ & $\begin{array}{l}12 / 62 \\
(19 \%)\end{array}$ & $\begin{array}{l}43 / 105 \\
(41 \%)\end{array}$ & $\begin{array}{l}12 / 96 \\
(13 \%)\end{array}$ \\
\hline $\begin{array}{l}\text { 9. BMI Screening and Lifestyle Counseling: a. IF a patient } \\
\text { has rheumatoid arthritis THEN their body mass index (BMI) } \\
\text { should be documented at least once every year. }\end{array}$ & $\begin{array}{l}11 / 170 \\
(6 \%)\end{array}$ & $\begin{array}{r}6 / 159 \\
(4 \%)\end{array}$ & $\begin{array}{l}6 / 63 \\
(10 \%)\end{array}$ & $\begin{array}{l}6 / 62 \\
(10 \%)\end{array}$ & $\begin{array}{l}5 / 107 \\
(5 \%)\end{array}$ & $\begin{array}{l}0 / 97 \\
(0 \%)\end{array}$ \\
\hline $\begin{array}{l}\text { 9b. If they are overweight or obese according to national } \\
\text { guidelines they should be counseled to modify their lifestyle. }\end{array}$ & $\begin{array}{c}10 / 111 \\
(9 \%)\end{array}$ & $\begin{array}{l}5 / 103 \\
(5 \%)\end{array}$ & $\begin{array}{l}1 / 40 \\
(3 \%)\end{array}$ & $\begin{array}{l}2 / 39 \\
(5 \%)\end{array}$ & $\begin{array}{c}9 / 71 \\
(13 \%)\end{array}$ & $\begin{array}{l}3 / 64 \\
(5 \%)\end{array}$ \\
\hline $\begin{array}{l}\text { 10. Minimizing corticosteroid usage: IF a patient with } \\
\text { rheumatoid arthritis is on oral corticosteroids THEN there } \\
\text { should be evidence of intent to taper off the corticosteroids or } \\
\text { reduce to the lowest possible dose. }\end{array}$ & $\begin{array}{l}56 / 57 \\
(98 \%)\end{array}$ & $\begin{array}{l}28 / 28 \\
(100 \%)\end{array}$ & $\begin{array}{l}25 / 26 \\
(96 \%)\end{array}$ & $\begin{array}{c}18 / 18 \\
(100 \%)\end{array}$ & $\begin{array}{c}31 / 31 \\
(100 \%)\end{array}$ & $\begin{array}{c}10 / 10 \\
(100 \%)\end{array}$ \\
\hline $\begin{array}{l}\text { 11. Communication about risks/benefits of anti- } \\
\text { inflammatories in patients at high risk of CV events: IF a } \\
\text { patient has rheumatoid arthritis AND has established } \\
\text { cardiovascular disease OR is at intermediate or high } \\
\text { cardiovascular risk AND is on a non-steroidal anti- }\end{array}$ & $\begin{array}{l}2 / 23 \\
(9 \%)\end{array}$ & $\begin{array}{l}0 / 17 \\
(0 \%)\end{array}$ & $\begin{array}{c}0 / 4 \\
(0 \%)\end{array}$ & $\begin{array}{c}0 / 6 \\
(0 \%)\end{array}$ & $\begin{array}{c}2 / 19 \\
(11 \%)\end{array}$ & $\begin{array}{l}0 / 11 \\
(0 \%)\end{array}$ \\
\hline
\end{tabular}


inflammatory drug (NSAID or Cox-2 inhibitor) THEN a

discussion about the potential cardiovascular risks should

occur and be documented.

*Note: QIs are reported either over a one or a two-year measurement basis (as indicated in the table). The denominators vary for each indicator as shown depending on the eligibility criteria for each denominator criteria as published in [9] and rational for exclusion from the denominators is available upon request. Overall, there 11 patients who were not eligible for inclusion in any of the denominator for indicators in year 2 due to lack of follow-up or new incident cardiovascular disease after year 1.

**Note the denominator for this indicator in Y2 does not include patients who were documented to be non-smokers in Y1.

*** The final part of this indicator "AND if screening is abnormal, this information should be communicated to the primary care provider for appropriate follow-up and management if indicated" (was not reported on due to very small sample sizes in the denominator).

**** Patients at high or intermediate risk for diabetes include patients with the following risk factors: family history of type 2 diabetes in a first degree relative; history of metabolic syndrome; obesity or overweight (body mass index $\geq 25 \mathrm{~kg} / \mathrm{m} 2$ ); steroid use; history of gestational diabetes or a macrosomic infant; history of impaired fasting glucose $(>=6.1 \mathrm{mmol} / \mathrm{L})$, or $\mathrm{HbA} 1 \mathrm{C}>=6.0 \%$; history of hypertension (blood pressure $\geq 140 / 90 \mathrm{mmHg}$ ); member of a high risk population (e.g. Aboriginal, Asian, Hispanic, South Asian, African, Pacific Islanders); high risk based on validated diabetes risk calculators or high or intermediate cardiovascular risk based on cardiovascular risk calculators (e.g., Framingham risk score)."

Abbreviations: Body Mass Index (BMI), Cardiovascular (CV), Early Rheumatoid Arthritis (ERA), Non-steroidal anti-inflammatory (NSAID), primary care physician (PCP), Year (Y) 
Table 4. Assessment of inter-rater reliability* for each cardiovascular quality indicator in 48 randomly selected charts

\begin{tabular}{|c|c|c|c|c|c|}
\hline Quality Indicator & \multicolumn{2}{|c|}{ Kappa } & \multicolumn{2}{|c|}{$\begin{array}{l}\text { Percent agreement } \\
(\mathrm{N}=48)\end{array}$} & Interpretation \\
\hline $\begin{array}{l}\text { 1. Communication of } \\
\text { increased CV risk in RA }\end{array}$ & \multicolumn{2}{|c|}{$0 *$} & \multicolumn{2}{|c|}{$47(98 \%)$} & $\begin{array}{l}\text { Falsely low due } \\
\text { to low } \\
\text { performance on } \\
\text { the indicator }\end{array}$ \\
\hline 2. $\mathrm{CV}$ risk assessment & \multicolumn{2}{|c|}{1.0} & \multicolumn{2}{|c|}{$48(100 \%)$} & $\begin{array}{l}\text { Perfect } \\
\text { agreement }\end{array}$ \\
\hline $\begin{array}{l}\text { 2b. If intermediate or high risk } \\
\text { according to guidelines THEN } \\
\text { recommended that treatment of } \\
\text { RF be initiated. }\end{array}$ & \multicolumn{2}{|c|}{$0 *$} & \multicolumn{2}{|c|}{$41(85 \%)$} & $\begin{array}{l}\text { Falsely low due } \\
\text { to low } \\
\text { performance on } \\
\text { the indicator }\end{array}$ \\
\hline \multirow{2}{*}{$\begin{array}{l}\text { 3. Smoking status and } \\
\text { cessation counseling }\end{array}$} & Y1 & $\mathbf{Y 2}$ & Y1 & $\mathbf{Y 2}$ & \\
\hline & 0.28 & 0.59 & $\begin{array}{c}31 \\
(65 \%)\end{array}$ & $\begin{array}{c}39 \\
(81 \%)\end{array}$ & $\begin{array}{l}\text { Fair agreement } \\
\text { Y1 and } \\
\text { moderate } \\
\text { agreement Y2 }\end{array}$ \\
\hline $\begin{array}{l}\text { 3b. If smoker counseled to quit } \\
\text { smoking }\end{array}$ & 0.88 & 0.57 & $\begin{array}{c}46 \\
(96 \%)\end{array}$ & $\begin{array}{c}44 \\
(92 \%)\end{array}$ & $\begin{array}{l}\text { Almost perfect } \\
\text { agreement Y1 } \\
\text { and moderate } \\
\text { agreement Y2 }\end{array}$ \\
\hline 4. Screening for hypertension & 0.91 & 0.50 & $\begin{array}{c}46 \\
(96 \%)\end{array}$ & $\begin{array}{c}38 \\
(79 \%)\end{array}$ & $\begin{array}{l}\text { Almost perfect } \\
\text { agreement Y1 } \\
\text { and moderate } \\
\text { agreement Y2 }\end{array}$ \\
\hline $\begin{array}{l}\text { 5. Communication to PCP } \\
\text { about a documented high } \\
\text { blood pressure }\end{array}$ & 0.70 & 0.70 & $\begin{array}{c}41 \\
(85 \%)\end{array}$ & $\begin{array}{c}41 \\
(85 \%)\end{array}$ & $\begin{array}{l}\text { Substantial } \\
\text { agreement }\end{array}$ \\
\hline $\begin{array}{l}\text { 6. Measurement of a lipid } \\
\text { profile }\end{array}$ & \multicolumn{2}{|c|}{0.91} & \multicolumn{2}{|c|}{$46 / 48(96 \%)$} & $\begin{array}{l}\text { Almost perfect } \\
\text { agreement }\end{array}$ \\
\hline 7. Screening for diabetes: & \multicolumn{2}{|c|}{0.84} & \multicolumn{2}{|c|}{$44 / 48(92 \%)$} & $\begin{array}{l}\text { Almost perfect } \\
\text { agreement }\end{array}$ \\
\hline \multirow{2}{*}{$\begin{array}{l}\text { 7b. Yearly screening for } \\
\text { diabetes in patients at } \\
\text { intermediate or high risk** }\end{array}$} & Y1 & Y2 & Y1 & Y2 & \\
\hline & 0.75 & 0.61 & $\begin{array}{c}40 \\
(83 \%) \\
\end{array}$ & $\begin{array}{c}38 \\
(79 \%) \\
\end{array}$ & $\begin{array}{l}\text { Substantial } \\
\text { agreement }\end{array}$ \\
\hline 8. Exercise & 0.49 & 0.33 & $\begin{array}{c}37 \\
(77 \%)\end{array}$ & $\begin{array}{c}37 \\
(77 \%)\end{array}$ & $\begin{array}{l}\text { Moderate } \\
\text { agreement Y1 } \\
\text { and Fair } \\
\text { agreement Y2 }\end{array}$ \\
\hline
\end{tabular}




\begin{tabular}{|l|c|c|c|c|l|}
\hline $\begin{array}{l}\text { 9. BMI Screening and } \\
\text { Lifestyle Counseling }\end{array}$ & 0.85 & 0.63 & $\begin{array}{c}47 \\
(98 \%)\end{array}$ & $\begin{array}{c}44 \\
(92 \%)\end{array}$ & $\begin{array}{l}\text { Almost perfect } \\
\text { agreement Y1 } \\
\text { and substantial } \\
\text { agreement Y2 }\end{array}$ \\
\hline $\begin{array}{l}\text { 9b. If they are overweight or } \\
\text { obese according to national } \\
\text { guidelines they should be } \\
\text { counseled to modify their } \\
\text { lifestyle }\end{array}$ & 0.71 & 0.75 & $\begin{array}{c}41 \\
(85 \%)\end{array}$ & $\begin{array}{c}42 \\
(88 \%)\end{array}$ & $\begin{array}{l}\text { Substantial } \\
\text { agreement }\end{array}$ \\
\hline $\begin{array}{l}\text { 10. Minimizing corticosteroid } \\
\text { usage }\end{array}$ & 0.79 & 0.57 & $\begin{array}{c}43 \\
(90 \%)\end{array}$ & $\begin{array}{c}40 \\
(83 \%)\end{array}$ & $\begin{array}{l}\text { Substantial } \\
\text { agreement Y1 } \\
\text { and moderate } \\
\text { agreement Y2 }\end{array}$ \\
\hline $\begin{array}{l}\text { 11. Communication about } \\
\text { risks/benefits of anti- } \\
\text { inflammatories in patients at } \\
\text { high risk of CV events }\end{array}$ & 0.51 & 0.69 & $\begin{array}{c}42 \\
(88 \%)\end{array}$ & $\begin{array}{l}\text { Moderate } \\
\text { agreement Y1 } \\
\text { and substantial } \\
\text { agreement Y2 }\end{array}$ \\
\hline
\end{tabular}

The inter-rater reliability for 2 of 3 chart-reviewers was reported for each QI by calculating a Kappa score. The interpretation of the score is as follows: Below 0.0 poor; 0.00-0.20 Slight agreement; 0.21-0.40 Fair agreement; 0.41-0.60 Moderate agreement; 0.61-0.80 Substantial Agreement and 0.81-1.00 Almost Perfect agreement between reviewers.

* note due the way Kappa scores are calculated, these indicators have a high agreement but a low Kappa score and are falsely 0.

** Patients at high or intermediate risk for diabetes include patients with the following risk factors: family history of type 2 diabetes in a first degree relative; history of metabolic syndrome; obesity or overweight (body mass index $\geq 25 \mathrm{~kg} / \mathrm{m} 2$ ); steroid use; history of gestational diabetes or a macrosomic infant; history of impaired fasting glucose $(>=6.1 \mathrm{mmol} / \mathrm{L}$ ), or $\mathrm{HbA} 1 \mathrm{C}>=6.0 \%$; history of hypertension (blood pressure $\geq 140 / 90$ $\mathrm{mmHg}$ ); member of a high risk population (e.g. Aboriginal, Asian, Hispanic, South Asian, African, Pacific Islanders); high risk based on validated diabetes risk calculators or high or intermediate cardiovascular risk based on cardiovascular risk calculators (e.g., Framingham risk score)."

Abbreviations: Body Mass Index (BMI), Cardiovascular (CV), Primary Care Provider (PCP), Quality Indicator (QI), Rheumatoid Arthritis (RA), Risk Factors (RF), Year (Y) 